\title{
Ibilgailu elektrikoen potentzia-bihurgailuen hozte-metodoak
}

\author{
(Electric vehicles power modules cooling methods)
}

Itxaso Aranzabal*, Asier Matallana, Oier Onederra,
Iñigo Martinez de Alegria, David Cabezuelo

Universidad del País Vasco / Euskal Herriko Unibertsitatea UPV/EHU

*itxaso.aranzabal@ehu.eus

DOI: $10.1387 /$ ekaia.17053

Jasoa: 2015-10-01

Onartua: 2016-06-15

Laburpena: Ibilgailu elektrikoari loturiko potentzia-bihurgailuetan, korronte-dentsitate handitan (500 A ingurukoak) lan egiten duten IGBT transistoreak eta diodoak erabiltzen dira. Korronte altuak direla eta, handitu egiten dira gailu erdieroale horietan gertatzen diren kommutazio- eta kondukzio-galerak, eta ondorioz, potentzia-erdieroaleak berotu egiten dira. Moduluen efizientzia eta fidagarritasuna ziurtatzeko, beharrezkoa da hozte-sistema eraginkor eta egoki bat aukeratzea. Artikulu honetan, potentziabihurgailuen moduluen hozte-metodoak berrikusi eta eztabaidatuko dira.

Hitz-gakoak: ibilgailu elektrikoa, potentzia-bihurgailua, hozte-metodoak.

Abstract: The power inverter modules asociated to Electric Vehicles (EV) are
equipped with IGBTs and Diodes working at high currents that can reach 500 A. The
high currents increase power losses, which become in heat and reduce the efficiency of
the semiconductor. To ensure high power density power inverters reliability and fiabil-
ity is necessary to design very efficient cooling systems. In this paper power inverter
modules different cooling options will be reviewed. Advantages and disadvantages of
such systems will be highlighted.

Keywords: electric vehicle, power electronic module, cooling system.

\section{SARRERA}

Ibilgailu elektrikoari loturiko potentzia-bihurgailuetan, korronte-dentsitate handitan (500 A ingurukoak) lan egiten duten IGBT transistoreak eta diodoak erabiltzen dira. Korronte altuak direla eta, handitu egiten dira 
gailu erdieroale horietan gertatzen diren kommutazio-galerak $\left(P_{\text {loss sw }}\right)$ eta kondukzio-galerak $\left(P_{\text {loss,cond }}\right)$, eta ondorioz, potentzia-erdieroaleak berotu egiten dira. Gaur egun, ibilgailu elektrikoari dagozkion IGBT moduluetan bero-fluxua 100-150 W/ $\mathrm{cm}^{2}$-koa da eta espero da hurrengo urteetan $500 \mathrm{~W} / \mathrm{cm}^{2}$-ra igotzea [1] (1. irudia).

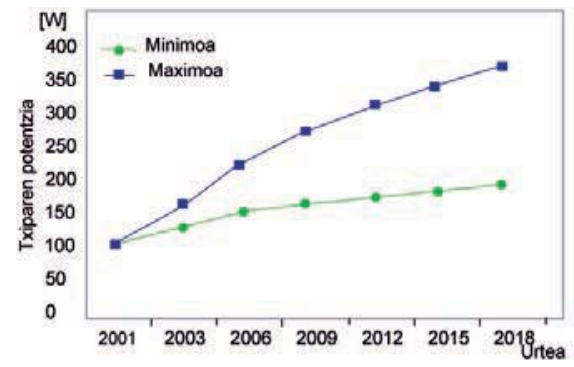

(a) Bero-fluxua handitzeko joera.

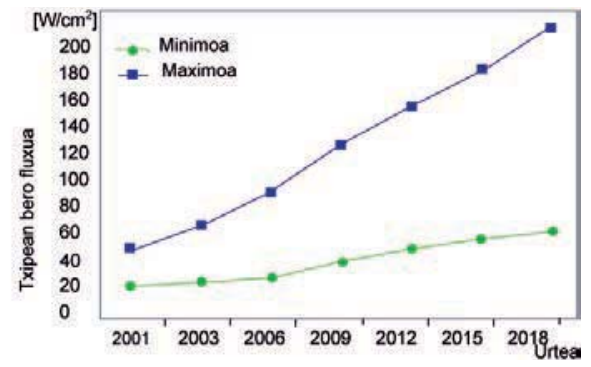

(b) Korronte-dentsitatea handitzeko joera.

1. irudia. Bero-fluxua eta korronte-dentsitatea handitzeko joera.

Alde horretatik, bermatu beharra dago erdieroaleen juntura-tenperaturak $\left(T_{j}\right)$ ez duela fabrikatzaileak emandako balio maximoa gainditzen (150 ${ }^{\circ} \mathrm{C}$ ingurukoa). Hori oso garrantzitsua da, gehiegizko tenperaturaren eraginez apurtzen baitira potentzia-erdieroaleen $\% 55$, gutxi gorabehera (2. irudia).

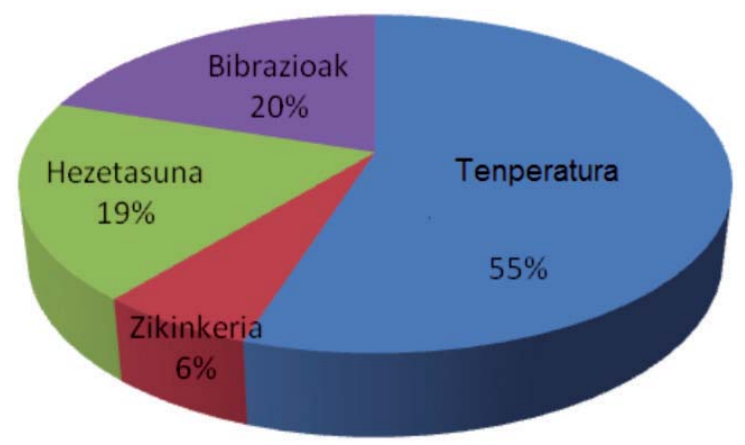

2. irudia. Potentzia-bihurgailuen moduluen apurketa eragiten duten arrazoi nagusiak.

Sistemaren funtzionamenduan tenperatura $10{ }^{\circ} \mathrm{C}$ igotzen den bakoitzean, bikoiztu egiten da sistemaren hutsegite-ratioa. Beraz, zenbat eta funtzionamendu-tenperatura baxuagoa izan, hainbat eta luzeagoa izango da erdieroalearen bizi-iraupena. 
Ibilgailu elektrikoen potentzia-bihurgailuen hozte-metodoak

\section{HOZTE-METODOEN SAILKAPENA}

Gaur egun, hozte-metodoak ondoren ageri diren eran sailkatu daitezke funtsean:

- Konbekzio naturalean (natural air cooling, ingelesez) eta aire-konbekzio bortxatuan (forced air cooling, ingelesez) oinarritutako hozte-metodoak.

- Hozte likidoan (liquid cooling, ingelesez) oinarritutako metodoa.

- Irakitean eta fase-aldaketan (two-phase cooling, ingelesez) oinarritutako hozte-metodoa.

\subsection{Konbekzio naturalean eta bortxatuan oinarritutako hozte-metodoak}

Nahiz eta konbekzio naturalean eta konbekzio bortxatuan oinarritzen diren hozte-metodoak gaur egun aplikazio askotan oraindik erabiltzen diren, arazoak izan ditzakete ibilgailu elektrikoak ezartzen dituen baldintzak kontuan hartzen badira: giro-tenperatura altuak, hezetasuna, bibrazioak, zikinkeria, eta abar. Horrez gain, ibilgailu elektrikoan erabiltzen den airez hoztutako aluminiozko bero-disipadore batek, pisu handiegia du, ibilgailuak onartu ahal duena baino handiagoa [22]. Halere, gaur egun oraindik balizko aukera izaten jarraitzen du. Kontuan hartu behar da autoa mugimenduan dagoenean, aire-fluxu handia sortzen duela bere inguruan, eta aire-korronte hori oso aprobetxagarria izan daitekeela (abiadura handitan). 3. irudiak, aire-disipadore batez hoztutako potentzia-modulu bat erakusten du.

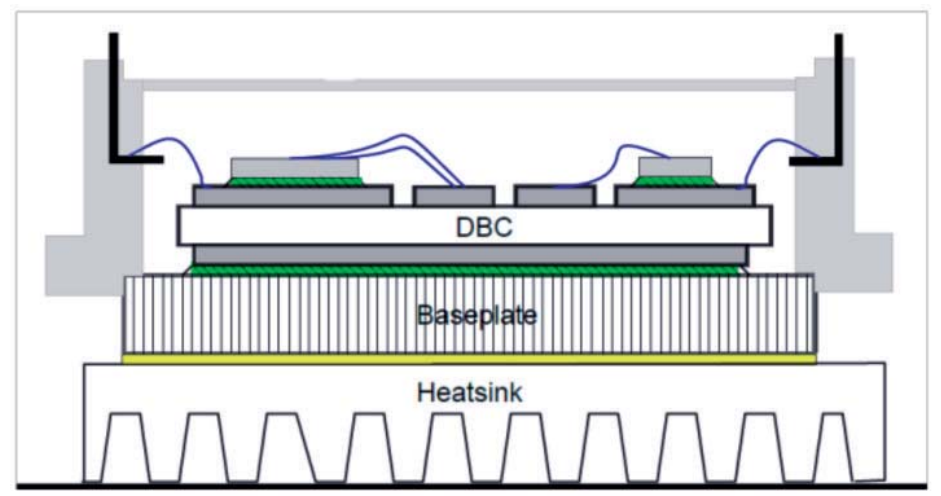

3. irudia. Aire-disipadore batez hoztutako potentzia-modulua.

$[3,4,5]$ ikerketa-lanetan konbekzio naturalean oinarritutako bero-disipadoreen fidagarritasuna bermatzeko dauden hainbat metodologia eztabaidatzen dira. 


\subsection{Hozte likidoa}

Hozte likidoan oinarrituko metodoek beroa era eraginkorrean disipatzen dute. Helburu nagusia potentzia-moduluaren eta hozte-fluidoaren arteko erresistentzia termikoa $\left(R_{t h}\right)$ murriztea da.

Hozte likidoan oinarritutako metodoak bi sailetan bereizten dira nagusiki: hozte likido zuzena eta zeharkakoa. Lehenengoan hoztailearen eta hoztu beharreko gainazalaren artean kontaktu zuzena dago (4(a). irudia). Zeharkako hozte likidoan, berriz, ez dago erdieroalearen eta hoztailearen arteko kontaktu zuzenik (4(b). irudia).

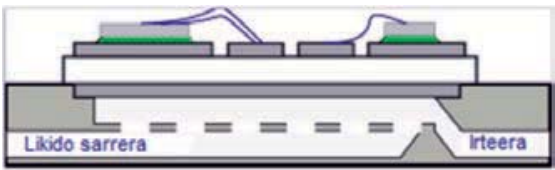

(a) Hozte likido zuzena.

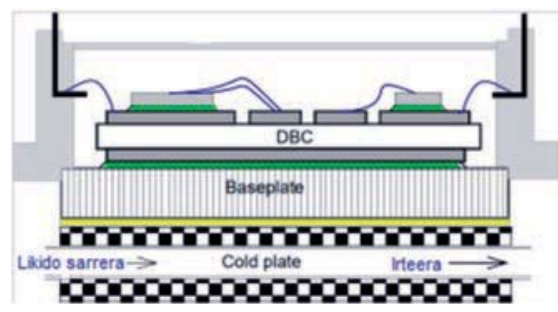

(b) Zeharkako hozte likidoa.

4. irudia. Hozte likidoa.

Era berean, erabilitako hoztailearen arabera, beste modu honetan ere sailka daitezke:

- Fase bakarreko sistemak: hauetan ura edo ur/glikol nahastea erabiltzen da hoztaile gisa. Bero-transferentzia konbekzio-prozesuaren eraginez gertatzen da.

- Hoztailearen fase-aldaketan oinarritutako hozte-sistemak: hauetan likido dielektrikoak erabiltzen dira hoztaile gisa eta bero-transferentzia hoztailearen fase-aldaketan oinarritzen da. Bero-xurgapena hoztailearen lurrinketa-prozesuan (hoztailea likido-egoeratik lurrinegoerara pasatzen denean), eta bero-askapena, hoztailearen kondentsazio-prozesuan (hoztailea lurrin-egoeratik likido-egoerara pasatzen denean).

Sistema bakoitzean erabili beharreko hoztaile egokiena aukeratzeak ezagutza sakona eskatzen du. Edonola ere, hoztaileak bateragarria izan behar du, eta aplikazio bakoitzak exijitzen dituen baldintza zehatz eta bereziak bete behar ditu $[6,7]$. 


\subsection{Zeharkako hozte-metodoak: Hozte-xaflak (Cold plate ak, ingelesez)}

Hozte-xaflak potentzia-moduluen bero-disipazio eraginkorra ziurtatzen dute baina ez dute eskaintzen erdieroalearen eta hoztailearen arteko kontaktu zuzenik. Bere eraginkortasuna erresistentzia termikoaren $\left(R_{t h}\right)$ menpekoa da eta azken hau, aldi berean, barne-egitura eta erabilitako materialen araberakoa da. Zenbat eta erresistentzia termiko txikiagoa orduan eta eraginkortasun termiko hobea [9]. Aldi berean, potentzia-moduluaren eta cold plate aren arteko juntura egokia ziurtatzeko TIM (Thermal Interface material, ingelesez) geruza beharrezkoa dutenez gero, beroa askatzeko eraginkortasun termikoa nabarmen jaisten da.

Gaur egun, fabrikazioan erabilitako teknologiaren arabera, era askotako cold plate ak aurki daitezke merkatuan (5. irudia).

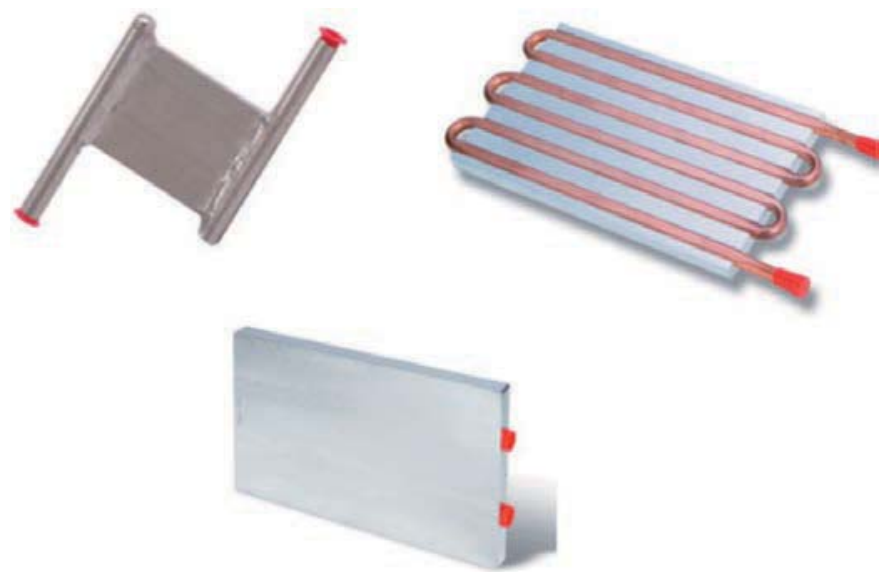

5. irudia. Teknologia ezberdina erabiltzen duten Cold plate ak.

\subsection{Hozte-metodo zuzenak}

Hozte-metodo zuzenetan hoztailearen eta hoztu beharreko gainazalaren artean kontaktu zuzena dago. Potentzia-moduluaren eta bero-disipatzailearen (heatsink, ingelesez) artean gehienetan agertzen den TIM geruza ezabatzea ahalbidetzen du. Azken hau, gailu erdieroalearen eta hoztailearen arteko erresistentzia termikoaren \% 30-\% 50 denez, geruza hau ezabatzerakoan potentzia-moduluaren erresistentzia termiko totala nabarmen jaisten da [22]. Ondorioz, beroa askatzeko eraginkortasun termikoa handitu egiten da. 


\subsubsection{Pin-hegalak (Pin Fins, ingelesez)}

Metodo hau, pin itxurako pin-hegalez (pin fins, ingelesez) osaturik dagoen base-plater (base plate, ingelesez) (AlSiCez edo $\mathrm{AlCz}$ osaturikoa gehienetan) baten oinarritzen da. Base-plater hau hoztailearen sarrera- eta irteera-konexioak dituen bainuontzi batean mihiztatzen da. Horrela, base-platerraren eta hoztailearen arteko kontaktu zuzena lortzen da, eta aldi berean, pin-hegalen (Pin fin, ingelesez) eraginez, bien arteko kontaktuazalera ere nabarmen handitzen da. Honek bero-trukatze handia eragiten du (6. irudia). [10] ikerketa lanean metodo honek ekartzen dituen hobekuntzak aztertzen dira sakon.

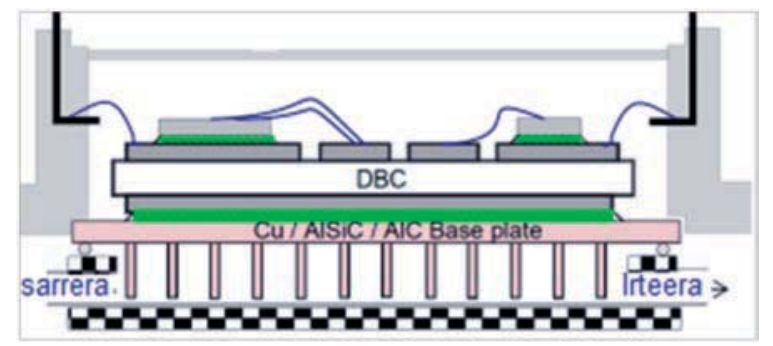

6. irudia. Pin-hegal (Pin fin, ingelesez) teknologiaz hozturiko potentzia-modulu baten adibidea.

\subsubsection{Ihinztatze-hoztea (Spray cooling, ingelesez) eta Jet-impignement} hoztea (jet impignement cooling, ingelesez)

Ihinztatze-hozte (Spray cooling, ingelesez) sistemak, hoztailea potentzia-moduluaren hoztu beharreko gainazalaren gain ihinztatzen du, eta, ondorioz, hoztaileak beroa xurgatu egiten du eta tanta fin bihurtzen da (7. iru-

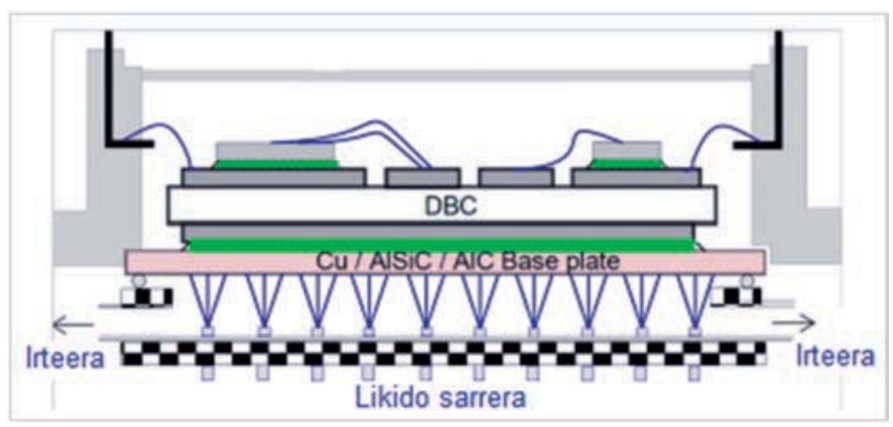

7. irudia. Ihinztatze-hozte (Spray cooling, ingelesez) teknologiaz hozturiko potentzia-modulu baten adibidea. 


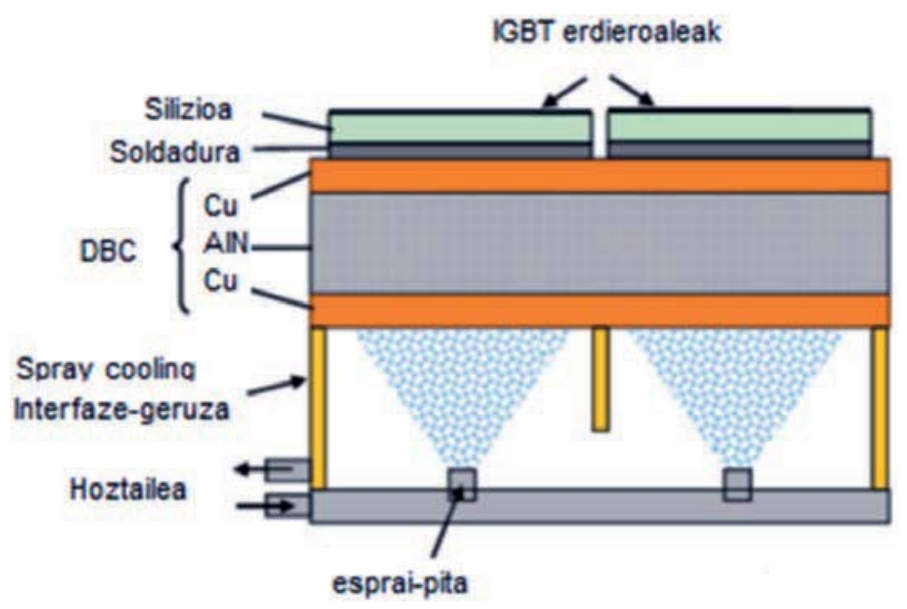

8. irudia. Ihinztatze-hozte (Spray cooling, ingelesez) teknologia.

dia eta 8. irudia). Bero-trukea teknika ezberdinak konbinatuz lortzen da. Alde batetik, hoztailearen eta hoztu beharreko gainazalaren arteko bero-trukea, eta beste alde batetik, hoztailearen fase-aldaketan gertatzen den berotrukea. Hori horrela izanda, hoztaile-emari txikiarekin bero-transferentziaren koefiziente handiak lortzen dira eta, ondorioz, hoztailea garraiatzeko sistema arinagoak eta trinkoagoak diseinatzea posible egiten du [11].

Bestalde, teknika honek, hoztu beharreko gainazala, hoztailearen saturazio-tenperatura eremuan mantentzea lortzen du.

Adibide bezala, National Renewable Energy Laboratory (NREL) ikerketa lantaldeak, teknologia honetan oinarritutako ikerketa lana biltzen du [2]. Bertan garatutako hozte-eskemak 150-200 W/ $\mathrm{cm}^{2}$-ko bero-fluxua disipatzea lortzen du.

Era berean, Jet-impignement hozte-metodoa erabiliz ere, hoztaile-emari txikiarekin, bero-fluxu handia askatzea lortzen da [1](9. irudia). Ihinztatzehozte sistemarekin alderatuz, ihinztagailua ezabatzen denez gero, fluidoaren dinamika sinpleagoa da eta zarata-maila ere murrizten du.

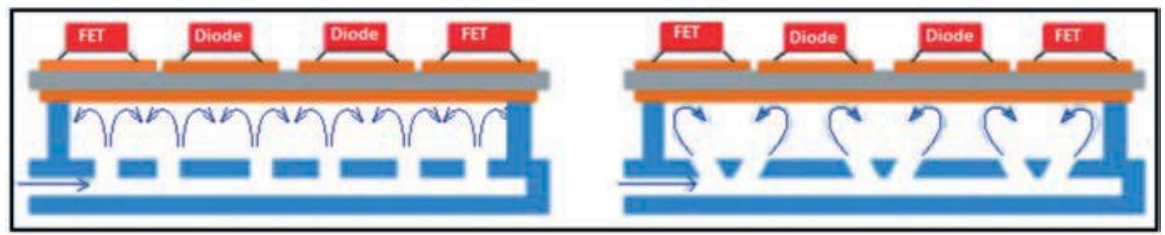

9. irudia. Jet-impignement hozte-teknologia. 
Era berean, gaur egun, teknologia hauetan kontuan izan beharreko parametro garrantzitsuenak aztertu eta eztabaidatzen dituen hainbat ikerketa-lan argitaratu dira $[16,17,18,19]$. Ibilgailu elektrikoaren alorrean egindako beste hainbat ikerketa-lanek ere $[12,13,14]$ emaitza eraginkorrak erakusten dituzte.

\subsubsection{Mikrokanal- eta minikanal-hoztea (Microchannels and minichannels cooling, ingelesez)}

Gaur egun ezagutzen diren metodorik eraginkorrenen artean dago teknika hau. Hoztailea hoztu beharreko gainazal guztian zehar jariatzen da eta, ondorioz, uniformetasun termiko bikaina eskaintzen du hozte-sistemak.

Hainbat ikerketa-lan burutu dira teknologia honen inguruan, eta kontuan izan beharreko parametro garrantzitsuenak (barneko kanalen geometria, erabilitako materiala, hoztaile mota, beroa disipatzeko gaitasuna, presio-jaitsiera, etab.) aztertu eta eztabaidatu dira [20,21].

Adibide bezala, Curamicek (Eschenbach, Alemania) teknologia honetan oinarritzen den kontzeptu barri bat sortu du. Mikrokanal-hozteak DBCaren (Direct Bond Copper, ingelesez) baitan txertatuta daude zuzenean [22] (10. irudia).
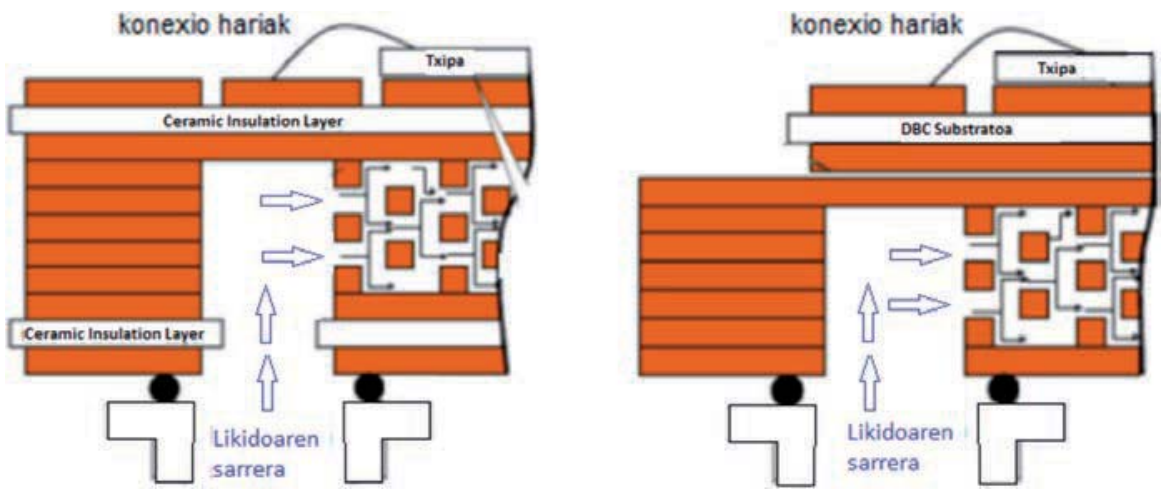

10. irudia. Mikrokanal-hozte (Microchannel, ingelesez) teknologia ezberdinak.

\subsection{Alde bikoitzeko hoztea (Double size cooling, ingelesez)}

Alde bikoitzeko hozte-metodoak, beroa erdieroalearen bi aldeetatik askatzea ahalbidetzen du. Horretarako, txipak bi DBC substratu artean mihiztatzen dira. Hori horrela izanda, hozte-likidoak moduluaren bi aldeetan eragina du, eta beroa bi aldeetatik disipatzea lortzen da. Ondorioz, potentzia-moduluaren erresistentzia termikoa eta tamaina murriztea posible egi- 
ten du. Bestalde, alde bikoitzeko egitura berri honek beharrezko egiten du erdieroalearen mihiztatze-prozesuan konexio-hariak desagerraraztea.

11. irudiak alde bikoitzeko hozte-metodoan oinarritzen den modulu baten oinarrizko egitura erakusten du.

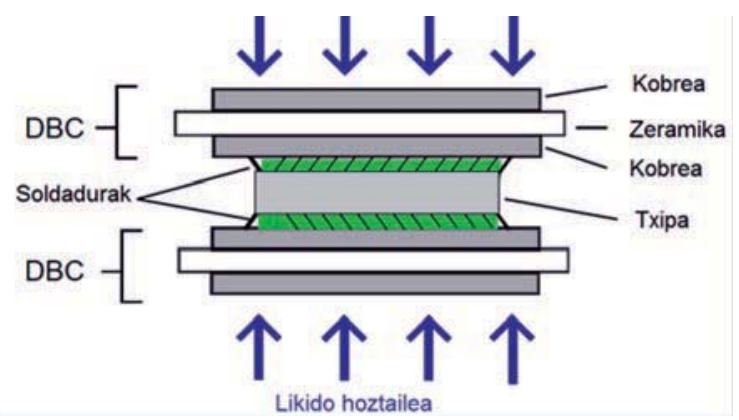

11. irudia. Alde bikoitzeko hozte-metodoan oinarritutako modulu baten oinarrizko egitura.

Denso Corporation, Cambridge, Nottingham eta Oxfordeko unibertsitateek elkarlanean burututako ikerlanean [23], teknologia honetan oinarritutako modulua diseinatu dute. Txipak bi DBC substratu artean mihiztatzen dira eta jet-impignement hozte-metodoaren bitartez hozten dira. Hori horrela izanda, ur-zurrustak moduluaren bi aldeetan eragina dute, eta beroa bi aldeetatik disipatzea lortzen da.

Egitura berekoa da Semikronek Skin Module teknologian oinarritutako modulua ere [24]. Orobat, Toyota Lexus LS600 ibilgailu elektrikoaren potentzia-moduluaren hozte-metodo honetan oinarrituz diseinatu da. Diseinu berri honetan, estruktura bakar batean pilatzen dira moduluak (12. irudia).

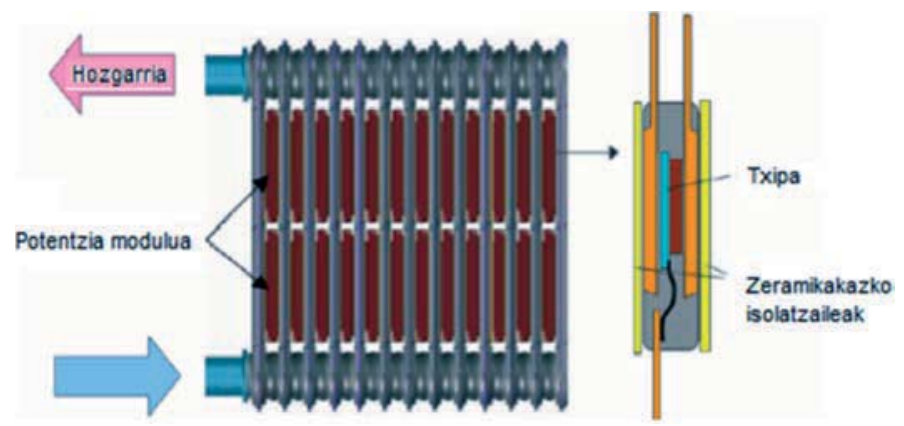

12. irudia. Toyota Lexus LS600 ibilgailu elektrikoaren potentzia-modulua. 


\subsection{Hozte termoelektrikoa}

Aurreko ataletan azaldutako hozte-metodoek bero-fluxu handiak eta erresistentzia termiko txikia eskaintzen dute. Baina ordea, hozte-prozesua DBC gainazal guztiaren gain egiten dutenez gero, IGBT gailu bakoitzaren baitan agertzen diren tenperatura desberdinak kontrolatzea ezinezko bihurtzen da [25]. 13. irudiak hozte-xafla teknologiako disipadore batean, $30{ }^{\circ} \mathrm{C}$ tan dagoen hoztailea erabiliz, IGBT gailuaren baitan lortutako tenperaturaprofila erakusten du hurrenez hurren.
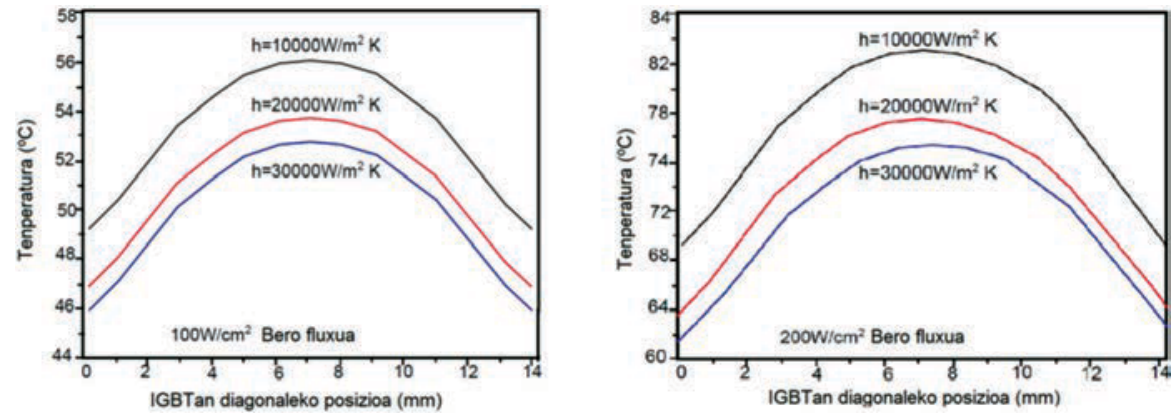

13. irudia. IGBT gailuan lortutako tenperatura-profila.

Hori horrela izanda, interesgarria da nabarmentzea nola, nahiz eta berotransferentzia koefizientea handitu eta beraz potentzia-moduluaren tenperatura jaitsi, IGBT gailuaren barneko tenperaturaren profilak ez duen bere itxura parabolikoa galtzen. Hau guztia kontutan izanik, IGBT gailuaren diseinu elektrikoaren ikuspuntutik, hutsegite-iragarpen, estres termiko eta fidagarritasunaren aldetik, beharrezkoa da gailuaren tenperatura ahal den eta uniformeen mantentzea.

Hori horrela, hozte termoelektrikoak, Peltier, Seeback eta Thomson efektuetan oinarrituz [27], IGBT gailuaren isotermalizazioa ahalbidetzen du: era egokian konfiguratutako gailu termoelektriko batetik zehar, korronte batek zeharkatzen duenean, beroa gailuaren alde batetik kontrako aldera garraiatzen da.

[25] ikerketa-lanean, egitura hibrido berriztagarri bat proposatzen da: hozte-xafla potentzia-modulu osoa hozteko erabiltzen da eta hozte termoelektrikoak IGBT gailuari uniformetasun termikoa ematen dio (14. irudia). 

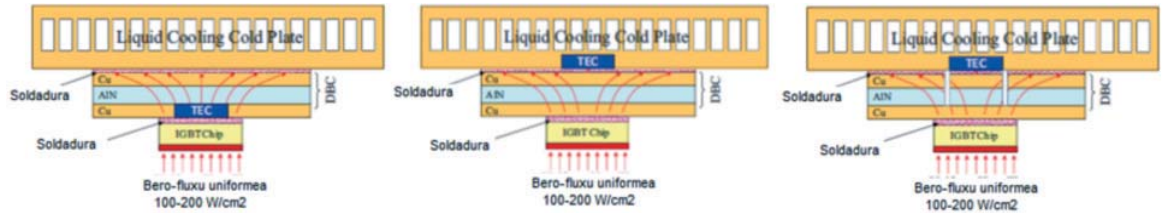

14. irudia. IGBT gailuaren tenperatura uniforme mantentzeko diseinatutako sistema hibridoaren topologia ezberdinak.

\subsection{Fase-aldaketan oinarritutako sistemak}

Fase-aldaketan oinarritutako hozte-sistemek fase sinplean oinarritutakoekin alderatuz abantaila anitz eskaintzen dituzte.

Hoztailearen lurruntze-bero sorra (hots, egoera-aldaketa gertatzen den bitartean, eta tenperatura aldatzen ez delarik, substantzia batek masa-unitateko xurgatzen edo askatzen duen bero-kantitatea) egoera sinplekoekin alderatuz, magnitude-ordenakoen bi halako da [26]. Ondorioz, hozte-potentzia are handiagoa da. Era berean, egoera-aldaketari dagokion bero-transferentziaren koefizientea, egoera sinplean oinarritzen diren hozte-metodoetan baino askoz handiagoa da [8].

Era berean, hozte-teknika honek beste onura batzuk ere eskaintzen ditu: moduluaren bolumena, pisua eta kostua. Izan ere, beste metodo batzuek eskaintzen duten errendimendu bera lortzeko, hoztaile-emari txikiagoa behar da eta, ondorioz, hauek garraiatzeko hodiak, bonbak eta deposituak ere txikiagoak dira.

Bestalde, fase bikoitzeko konbekzio-prozesuei loturiko fisika ulertzea zailagoa da eta, beraz, errendimendu bera lortzeko esfortzu handiagoa eskatzen du. Aurreko ataletan aztertutako hozte-metodo batzuek ere (jet-impignement hoztea, ihinztatze-hoztea, hozte-xaflak), egoera-aldaketa zein egoera sinplean lan egiten duten hoztaileak erabili ahal dituzte.

\section{ETORKIZUNERAKO JOERAK ETA ERRONKAK}

Ibilgailu elektrikoak lan egiteko betekizun asko ezartzen ditu: korronte-dentsitate handiekin lan egiteko beharra, kommutazio-maiztasun handia, bero-fluxu handiak askatzeko gaitasuna, tenperatura-aldaketa nabarmenak jasateko gaitasuna, ingurumen ezatseginetan lan egiteko gaitasuna (bibrazioak, zikinkeria), eta abar. Bestalde, gailu erdieroaleen diseinu-teknologien ikerketan eman diren aurrepausu nabarmenak direla eta, korronte-dentsitate handitan lan egiteko gaitasun handia duten erdieroaleak diseinatu 
dira. Erronka, aldiz, erdieroaleen integrazioan (packaging, ingelesez) eta mihiztatze-teknologia ezberdinak ikertzean dago, eta bertan hozte-sistemak garrantzi handia du.

Potentzia-bihurgailuen fidagarritasuna, errendimendua eta efizientzia era kuantitatibo baten balioztatzeko ezinbestekoa da hainbat parametro tekniko (parametro elektriko, termiko eta termomekanikoak) aztertzea: inpedantzia termikoa (erresistentzia eta kapazitantzia), gailuaren operazio-tenperatura maximoa, erresistentzia- eta induktantzia-parasitoak, konduktantzia, gailuaren bizi-iraupena (power cycling eta thermal cycling), etab. Hori horrela, [28] ikerlanean, gaur egungo ibilgalu elektrikoen potentzia-moduluen mihiztatze-teknologietan ematen ari diren aurrerapausuak eta erronkak aztertzen dira.

Hozte-metodoei dagokionez, tendentzia hozte-likidoan oinarritutako sistemak dira: Pin-hegalak, ihiztatze-hoztea, jet-impignement hoztea, mikrokanal-hoztea. Era berean, alde bikoitzeko hozte-metodoak, fase-aldaketan oinarritutako hozte-metodoak eta hozte termoelektrikoak beroa azkatzeko gaitasuna nabarmen handitzen dute.

\section{BIBLIOGRAFIA}

[1] BHUNIA, A., CHANDDRASEKARAN, S., CHEN,C.L. 2007. «Performance improvement of a power conversion module by liquid micro-jet impingement cooling», IEEE Transactions on Components and Packaging Technologies, (30)2, 309-316.

[2] MUDAWAR, I., BHARATHAN,D., KELLY, K., NARUMANCHI,S., 2008. «Two-phase spray cooling of hybrid vehicle electronics», in Proc. of Intersociety Conference onThermal and Thermomechanical Phenomena in Electronic Systems (ITHERM), 1210-1221.

[3] WINTRICH, A., NICOLAI, U., TURSKY, W., REIMANN, T., SEMICRON (Ed.), 2011. «Application Manual Power Semiconductor,S emikron International $\mathrm{GmbH} »$.

[4] BAR-COHEN, A., BAHADUR, R., IYENGAR, M., 2006. «Least-energy optimization of air-cooled heat sinks for sustainability-theory, geometry and material selection». Energy (31)5, 579-619.

[5] RODGERS, P., EVELOY, V., 2013. «Air cooled heat sink design optimization in free convection», in Proc. of Semiconductor Thermal Measurement and Management Symposium (SEMI-THERM), 170-172.

[6] S. M.R., 2005. «Potential refrigerants for power electronics cooling», Oak Ridge National Laboratory.

[7] MOHAPATRA, S., LOIKITS, D., 2005. «Advances in liquid coolant technologies for electronics cooling», in Proc. of Semiconductor Thermal Measurement and Management Symposium (SEMI-THERM), 354-360. 
[8] SAUMS, D.,2011. «Applications of vaporizable dielectric fluid cooling for igbt power semiconductors», in Proc. of Semiconductor Thermal Measurement and Management Symposium (SEMI-THERM), 253-264.

[9] KANG, S., 2012. «Advanced cooling for power electronics», in Proc. of International Conference on Integrated Power Electronics Systems (CIPS), 1-8.

[10] LIANG, Z., LI, L., 2008. «Hybridpack2 - advanced cooling concept and package technology for hybrid electric vehicles», in Proc. of Vehicle Power and Propulsion Conference (VPPC), 1-5.

[11] KIM, J., 2007. «Spray cooling heat transfer: The state of the art International Journal of Heat and Fluid Flow», 28, 753-767.

[12] BOStANCI, H., VAN EE, D., SAARLOOS, B., RINI, D., CHOW, L., 2012. "Thermal management of power inverter modules at high fluxes via two-phase spray cooling», IEEE Transactions on Components, Packaging and Manufacturing Technology, 2, 1480-1485.

[13] TUREK, L., RINI, D., SAARLOOS, B., CHOW, L.,2008. «Evaporative spray cooling of power electronics using high temperature coolant», Proc. of Intersociety Conference on Thermal and Thermomechanical Phenomena in Electronic Systems (ITHERM).

[14] MERTENS, R., CHOW, L., SUNDARAM, K.B., CREGGER, R.B., RINI, D. TUREK, L., SAARLOOS, B.A., 2007. «Spray Cooling of IGBT Devices», Journal of Electronic Packaging. ASME.

[15] OLESEN, K., OSTERWALD, F., TONNES, M., DRABEK, R., EISELE, R., 2010. «Direct liquid cooling of power modules in converters for the wind industry», in Proc. of International Exhibition and Conference for Power Electronics, Intelligent Motion, Renewable Energy and Energy Management (PCIM), 742-747.

[16] BHUNIA, A., CHEN, C.L., 2005. «Jet Impignement Cooling of an Inverter Module in the Harsh Enviroment of a Hybrid Vehicle», Heat Transfer Division and Electronic and Photonic Packaging Division, 4, 561-567.

[17] GOULD, K., CAI, S., NEFT, C., BHUNIA, A.,2015. K. Gould, S. Cai, C. Neft, and A. Bhunia, «Liquid jet impingement cooling of a silicon carbide power conversion module for vehicle applications», IEEE Transactions on Power Electronics,30, 2975-2984.

[18] P.R. Parida, S.V. Ekkad, and K. Ngo, PARIDA, P.R., EKKAD, S.V., NGO, K., 2012. «Impingement-based high performance cooling configurations for automotive power converters», International Journal of Heat and Mass Transfer, 55(4), 834-847.

[19] KELly, K., ABRAhAN, T., BENNiON, K., BHARATHAN, D., NARUMANCHI, S., O'KEEFE, M., 2007. «Assessmant of Thermal Control Technologies for Cooling Electric Vehicle Power Electronics», International Electric Vehicle Symposium.

[20] JANKOWSKI, N., EVERHART, L., MORGAN, B., GEIL, B., MCCLUSKEY, P., 2007. «Comparing microchannel technologies to minimize the 
thermal stack and improve thermal performance in hybrid electric vehicles», in Proc. of Vehicle Power and Propulsion Conference (VPPC), 124-130.

[21] LEE, J., MUDAWAR, I., 2009. «Low-temperature two-phase micro-channel cooling for high-heat-flux thermal management of defense electronics», in Proc. of Intersociety Conference onThermal and Thermomechanical Phenomena in Electronic Systems (ITHERM), 132-144.

[22] SCHULZ-HARDER, J., 2009. «Efficient cooling of power electronics», in Proc of International Conference on Power Electronics Systems and Applications (PESA), 1-4.

[23] BUTTAY, C., RASHID, J., JOHNSON, C., IRELAND, P., UDREA, F., AMARATUNGA, G., MALHAN, R., 2007. «High performance cooling system for automotive inverters», in Proc. of European Conference on Power Electronics and Applications (EPE), 1-9.

[24] GOBL,C., FALTENBACHER, J., 2010. «Low temperature sinter technology die attachment for power electronic applications», in Proc. of International Conference on Integrated Power Electronics Systems (CIPS), 1-5.

[25] WANG, P., MCCLUSKEY, P., BAR-COHEN, A., 2013. «Hybrid Solidand Liquid-Cooling Solution for Isothermalization of Insulated Gate Bipolar Transistor Power Electronic Devices», IEEE Transactions on Components, Packaging and Manufacturing Technology, 3, 601-611.

[26] MUDAWAR, I.,2001. «Assessment of high-heat-flux thermal management schemes», IEEE Transactions on Components and Packaging Technologies, 24, 122-141.

[27] ANANDAN, S., RAMALINGAM, V., 2008. «Thermal Management of electronics: A Review of Literature», Thermal Science, 12, 26.

[28] ARANZABAL, I., MATALLANA, A., ONEDERRA, O., CABEZUELO, D., MARTINEZ DE ALEGRIA, I., 2016. «Estado actual y avances en las tecnologías de ensamblado de los módulos de potencia asociados al vehículo eléctrico», Seminario Anual de Automática, Electrónica Industrial e Instrumentación (SAAEI), 1-6. 